\title{
Assessing catastrophic and impoverishing effects of health care payments in Uganda
}

\author{
Brendan Kwesiga ${ }^{1 *}$, Charlotte M Zikusooka ${ }^{1}$ and John E Ataguba²
}

\begin{abstract}
Background: Direct out-of-pocket payments for health care are recognised as limiting access to health care services and also endangering the welfare of households. In Uganda, such payments comprise a large portion of total health financing. This study assesses the catastrophic and impoverishing impact of paying for health care out-of-pocket in Uganda.

Methods: Using data from the Uganda National Household Surveys 2009/10, the catastrophic impact of out-ofpocket health care payments is defined using thresholds that vary with household income. The impoverishing effect of out-of-pocket health care payments is assessed using the Ugandan national poverty line and the World Bank poverty line $(\$ 1.25 /$ day).

Results: A high level and intensity of both financial catastrophe and impoverishment due to out-of-pocket payments are recorded. Using an initial threshold of 10\% of household income, about $23 \%$ of Ugandan households face financial ruin. Based on both the \$1.25/day and the Ugandan poverty lines, about $4 \%$ of the population are further impoverished by such payments. This represents a relative increase in poverty head count of $17.1 \%$ and $18.1 \%$ respectively.

Conclusion: The absence of financial protection in Uganda's health system calls for concerted action. Currently, out-of-pocket payments account for a large share of total health financing and there is no pooled prepayment system available. There is therefore a need to move towards mandatory prepayment. In this way, people could access the needed health services without any associated financial consequence.
\end{abstract}

Keywords: Financial health protection, Out-of-pocket payments, Catastrophic payments, Impoverishment, Uganda

\section{Background}

Globally, health systems are called upon to ensure universal access to health care for their populations [1]. This requires that they ensure the availability of adequate and quality health services for everyone in need of them while consequently protecting them from the accompanying financial burden [2]. The reliance on out-of-pocket payments for health care is a major cause of financial hardship in families. The World Health Report 2010 notes that over 100 million people are pushed into poverty while over 150 million people incur excessive out-of-pocket health payments that place a heavy drain on their living standards [1]. Despite the call for health systems to adopt sustainable health financing mechanisms as a

\footnotetext{
* Correspondence: brendan.kwesiga@healthnetconsult.com

${ }^{1}$ HealthNet Consult, P.O. Box 35928, Kampala, Uganda

Full list of author information is available at the end of the article
}

path to universal coverage, most health systems in low income countries, particularly in sub-Saharan Africa, are still heavily dependent on out-of-pocket payments $[3,4]$.

In Uganda, user fees were introduced in 1993 as part of a package of economic reforms recommended by the World Bank to reduce the level of debt and macroeconomic stagnation [5]. The rationale for these restructurings was based on a theoretical argument related to the price inelastic demand for health care. It was hoped that the health sector would be able to raise its own revenue so as to improve the quality of its services [5,6]. However, the implementation of the user fee policy not only failed to achieve these objectives, it also resulted in decreased health care utilisation consequently increasing morbidity and mortality $[7,8]$. In response, user fees were abolished in 2001. The abolition was expected not only to increase access to health care but to reduce the financial burden on households.

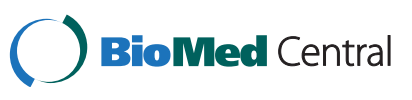


Indeed, public health care utilisation increased particularly among the poor after the removal of user fees [9-12]. However, among the rich, utilisation decreased to a rate even lower than before the elimination of the fees [12]. This is attributed to perceived differences in quality between the public and private sectors. Studies have revealed that the private health sector is the preferred provider for both the rich and the poor in Uganda [13-16]. The preference for private facilities which mainly rely on out-ofpocket payments has kept those payments high [17]. A further factor attributed to the high out-of-pocket payments is the presence of informal payments in the public health facilities [12]. It has been demonstrated that out-of-pocket payments as a percentage of private health expenditure in Uganda increased from $56.7 \%$ in 2000 to $64.8 \%$ in 2011 [18]. The most recent national health accounts exercise indicates that household contribution through out-of-pocket payments is the dominant source of health expenditure contributing about $50 \%$ of total health expenditure in the fiscal year 2009/10 [19].

Since illness is unpredictable, the consequent out-ofpocket payments incurred are likely to impose a financial burden on families. This is due to the impact of these payments on the allocation of the household's disposable income. For instance, the outlay compromises the consumption of other household necessities such as food, clothing education and housing [20]. These payments may also lead to a decrease in welfare leading to an increase in the level of poverty $[21,22]$. It has been argued, therefore, that in a fair and equitable health system, households should not pay more than a certain proportion of their total income for health out-of-pocket $[23,24]$. Exceeding such a threshold would make such payments catastrophic. These payments should also not push families into poverty or exacerbate their existing state of poverty [23]. These arguments form the basis for the methodologies used in measuring financial protection in a health system.

Various earlier studies have investigated aspects of the financial burden of illness in Uganda [12,17,19,25-27]. A review of the literature indicates that these published studies did not quantify the overall impoverishing impact of out-of-pocket health care payments. Furthermore, in this paper, financial catastrophe is assessed using a recent and generalised methodology developed by Ataguba [24] that is able to demonstrate more concern for poorer socioeconomic groups in society.

\section{Methods}

\section{Data}

The 2009/10 Uganda National Household Survey (UNHS) data is used for this study. This is a nationally representative survey conducted by the Uganda Bureau of Statistic (UBOS). The UNHS 2009/10 used the 2002 Uganda population and housing census sampling frame with a two-stage stratified sampling design to sample 6800 households. The first stage selects 712 enumeration areas (EAs). The EAs were allocated to ten sub-regions representing both urban and rural areas. In the second stage, ten households were systematically drawn from each of the selected EAs. UNHS data is available on the UBOS website (http://www.ubos.org/unda/index.php/catalog/51).

Data analysis utilises both ADePT version 5.2 software [28] and Stata version 11 [29]. All the estimates and the standard errors are adjusted for the sampling design using the appropriate sampling weights.

\section{Living standards and out-of-pocket measurements}

Total household consumption expenditure is used as a proxy for income. Household consumption is a preferred measure because it is less prone to fluctuation and is easier to collect in household surveys with less likelihood of being underreported when compared to income [30]. The components of household consumption expenditure include food, beverages and tobacco, durable, semi durable and non-durable household goods, and other frequently purchased goods and services. Total income is converted into an adult equivalent household income so as to account for household composition. The adult equivalent scale used in this study has been used elsewhere see $[31,32]$. It is estimated as:

$$
A E=(A+\beta C)
$$

where $A$ represents the number of household members aged 18 years and above while $C$ represents those below $18, \beta$ varies from 0.273 for the members below 1 year to 0.95 for members between 16 and 18 years.

Out-of-pocket payments used in this paper include consultation fees, medicines, facility charges and all the other health and medical costs not classified in the components above. These include expenditures on alternative/traditional medicines and fees.

\section{Assessing financial protection in a health system Catastrophic out-of-pocket health care payments}

Out-of-pocket health care payments are defined as catastrophic "if they exceed z\% of household income (or resources) but with $z$ increasing with income, that is, it is a rank-dependent threshold so that catastrophe is a function of where the individual, household or group sits in the income distribution range. Those at the upper end of the distribution face a greater proportion (threshold)" [24] p.314. The basic idea behind this reasoning is that such a threshold need not be the same for households of different socio-economic status as small out-of-pocket payments could be detrimental to those who are already poor. This method is a generalisation of that shown in 
[23]. In general, the methods developed in [24] may be used to replicate the results that use a constant threshold [23]. It also ensures that catastrophic impact is not only adjusted for vertical equity but is also able to adjust for the diminishing marginal utility of income.

If $y_{i}$ is total household income, $T_{i}$ is household total out-of-pocket payments and $Z_{c a t}$ is an initial threshold, then a rank dependent threshold $Z_{c a t}^{\prime}$ can be defined as:

$$
Z_{c a t}^{\prime}=w(p: \gamma) * Z_{c a t}
$$

where $\gamma$ is a parameter of aversion to inequality, $p$ is the household's percentile and $w(p: \gamma)=\gamma(1-p)^{(\gamma-1)}$ for $\gamma \in(0,1]$.

The restriction above implies that when $\gamma=1, Z_{c a t}^{\prime}=Z_{c a t}$ as in [23] while when $\gamma=0, Z_{c a t}^{\prime}$ is undefined. In this paper, following Ataguba [24], $\gamma=0.8$ while the initial thresholds are $\left(Z_{\text {cat }}\right)=5 \%, 10 \%, 15 \%$ and $25 \%$ of total household income.

Let $O_{i}^{\prime}$ represent the rank-dependent catastrophic overshoot (excess payment above a threshold) such that $O_{i}^{\prime}=\max \left(0,\left(T_{i} / y_{i}\right)-Z_{c a t}^{\prime}\right)$. If $E_{i}^{\prime}$ is a measure indicating whether a household exceeds the rank dependent threshold, then $E_{i}^{\prime}=1$ when $O_{i}^{\prime}>0$ and 0 otherwise. The rank-dependent headcount ratio $\left(H_{c a t}^{\prime}\right)$ is defined as:

$$
H_{c a t}^{\prime}=\frac{1}{N}\left(\sum_{i=1}^{N} E_{i}^{\prime}\right)=\mu_{E^{\prime}}^{\prime}
$$

where $\mu_{E^{\prime}}^{\prime}$ is the mean of $E^{\prime}$ and $N$ is the sample size. The headcount ratio measures the proportion of households that incur catastrophic payments.

The rank-dependent catastrophic gap $\left(G_{c a t}^{\prime}\right)$ which captures the deviations from the catastrophic threshold $Z_{c a t}^{\prime}$, is computed as:

$$
G_{c a t}^{\prime}=\frac{1}{N}\left(\sum_{i=1}^{N} O_{i}^{\prime}\right)=\mu_{O^{\prime}}^{\prime}
$$

where $\mu_{O^{\prime}}^{\prime}$ is the mean of the overshoots $\left(O_{i}^{\prime}\right)$.

\section{Impoverishment impact of out-of-pocket payments}

This is the increase in poverty that results from household's incurring out-of-pocket costs for health care [23]. If $P L_{0}$ is the poverty line and $Y_{i}$ is individual $i$ s prepayment adult equivalent household income, an individual is poor (i.e., prepayment poverty $\left.\left(P_{i}^{\text {pre }}\right)\right)$ if $Y_{i}<P L_{0}$. Therefore, prepayment poverty headcount ratio is computed as:

$$
H_{p o v}^{p r e}=\frac{1}{N} \sum_{i=1}^{N} P_{i}^{p r e}=\mu_{p^{p r e}}
$$

The short-fall from the poverty line $\left(g_{i}^{\text {pre }}\right)$ is defined as $\left(Y_{i}-P L_{0}\right)$ if $Y_{i}<P L_{0}$, and zero otherwise. The associated average prepayment poverty gap is defined as:

$$
G_{\text {pov }}^{\text {pre }}=\frac{1}{N} \sum_{i=1}^{N} g_{i}^{\text {pre }}=\mu_{g^{p r e}} .
$$

The normalised poverty gap is computed as:

$$
N G_{p o v}^{p r e}=G_{p o v}^{\text {pre }} / P L_{0} .
$$

When the superscripts "pre" are replaced with "post" the analogous post-payment poverty measures are obtained. The poverty impact of out-of-pocket payment is then defined as the difference between the relevant pre-payment and post-payment measures. In order to compute the percentage change in poverty as a result of out-of-pocket payments, relative ratios are obtained by dividing the difference between the prepayment and post payment poverty measures by the prepayment poverty measures.

Uganda's poverty line (PL1) which is region and location specific and the World Bank $\$ 1.25$ per day international poverty line (PL2) are used in this study. The maximum value of PL1 is in central urban (Shs. 32106.24 per month) while the least is for western rural (Shs. 28165.4 per month). The average value is Shs. 29,306.32 per month. Based on the Purchasing Power Parity (PPP), the $\$ 1.25 /$ day poverty line is equal to Shs. 27,923.18 per person per month.

Pen's parade of 'dwarfs and a few giants' that plots two income parades (i.e., gross income and income net of out-ofpocket payments) using a cumulative proportion of individuals ranked according to their gross household income [33], is also used in this paper. It illustrates the welfare decreasing effect of the out-of-pocket payment by showing the increase in the extent and depth of poverty as a result of such expenses.

Uganda's poverty line (PL1) which is region and location specific and the World Ethical clearance for the study was obtained from the Uganda National Council of Science and Technology (REF: SS 2463) and the Health Research Ethical Committee (HREC) of the University of Cape Town (REF: 248/2012).

\section{Results}

Household catastrophic out-of-pocket health payments

As indicated in Table 1, a large number of households spend a substantial share of their total income on outof-pocket health care. The proportion of households that spend above the thresholds varies depending on the initial threshold. With a 5\% initial threshold for example, the catastrophic headcount ratio is estimated at $38 \%$.

Table 1 Household catastrophic out-of-pocket health payments results for variable thresholds

\begin{tabular}{lllll}
\hline & \multicolumn{4}{l}{ Initial thresholds } \\
\cline { 2 - 5 } & $\mathbf{5 \%}$ & $\mathbf{1 0 \%}$ & $\mathbf{1 5 \%}$ & $\mathbf{2 5 \%}$ \\
\hline Headcount ratio & $38.0 \%$ & $22.8 \%$ & $15.3 \%$ & $6.7 \%$ \\
Gap & $3.8 \%$ & $2.5 \%$ & $1.7 \%$ & $0.8 \%$ \\
\hline
\end{tabular}

Source: Authors' computations based on UNHS 2009/2010. Note: The parameter of aversion to inequality, $\gamma=0.8$. 
Table 2 Impoverishment analysis results UNHS 2009/2010

\begin{tabular}{|c|c|c|c|c|c|c|}
\hline & \multicolumn{3}{|c|}{ PL 1 (Uganda's poverty line) $^{\mathrm{a}}$} & \multicolumn{3}{|c|}{ PL 2 (\$1.25) } \\
\hline & $\begin{array}{l}\text { Gross } \\
\text { (A) }\end{array}$ & $\begin{array}{l}\text { Net } \\
\text { (B) }\end{array}$ & $\begin{array}{l}\text { Relative } \\
(\mathrm{B}-\mathrm{A}) /(\mathrm{A})\end{array}$ & $\begin{array}{l}\text { Gross } \\
\text { (C) }\end{array}$ & $\begin{array}{l}\text { Net } \\
\text { (D) }\end{array}$ & $\begin{array}{l}\text { Relative } \\
\text { (D-C)/(C) }\end{array}$ \\
\hline Headcount ratio & $24.5 \%$ & $28.7 \%$ & $17.1 \%$ & $22.7 \%$ & $26.8 \%$ & $18.1 \%$ \\
\hline Normalised gap & $6.7 \%$ & $8.1 \%$ & $20.9 \%$ & $6.3 \%$ & $7.6 \%$ & $20.6 \%$ \\
\hline
\end{tabular}

Source: Authors' computations based on UNHS 2009/2010.

Note: ${ }^{a}$ Average poverty line is Shs. $29,306.32$ (\$1.31) per month.

This represents over two million households based on the population estimate of about six million households in the UNHS 2009/10. The catastrophic headcount ratio decreases to $22.8 \%$ at the $10 \%$ initial threshold.

As also demonstrated in Table 1 , the catastrophic health payments gap varies from $3.8 \%$ (at the $5 \%$ initial threshold) to $0.8 \%$ at an initial threshold of $25 \%$. This indicates that not only is the number of households that incur catastrophic out-of-pocket payments (defined by exceeding those thresholds) high, but households also substantially exceed these thresholds.

\section{Impoverishment effect of out-of-pocket payments}

As demonstrated in Table 2, using the Ugandan poverty line, out-of-pocket payments led to a $4.2 \%$ rise in poverty head count ratio. This represents over one million more Ugandans being pushed below the poverty line. The normalised poverty gap increased by about $1.4 \%$ representing about $21 \%$ relative increment. A similar pattern is observed using the World Bank $\$ 1.25$ a day poverty line (see Table 2).
The Pen's chart in Figure 1 indicates that out-ofpocket payments lead to a significant decrease in household welfare even increasing the extent of poverty among the currently non-poor. This is indicated by the decrease in household consumption expenditure shown by the "paint drips".

\section{Discussion}

The results indicate a lack of financial protection in Uganda's health system. A very high percentage of Ugandan households incur financial catastrophe irrespective of the threshold considered and these out-ofpocket payments impoverish about $4 \%$ of Ugandans representing over $17 \%$ relative raise in poverty in the country. Since out-of-pocket health care payments account for a substantial share of household budget, they are likely to compromise the consumption of other basic necessities [20,34].

The results relating to financial catastrophe in this paper follow similar patterns to those of previous studies around the financial burden of out-of-pocket payments in Uganda and elsewhere [12,24,27,35,36]. Although, to

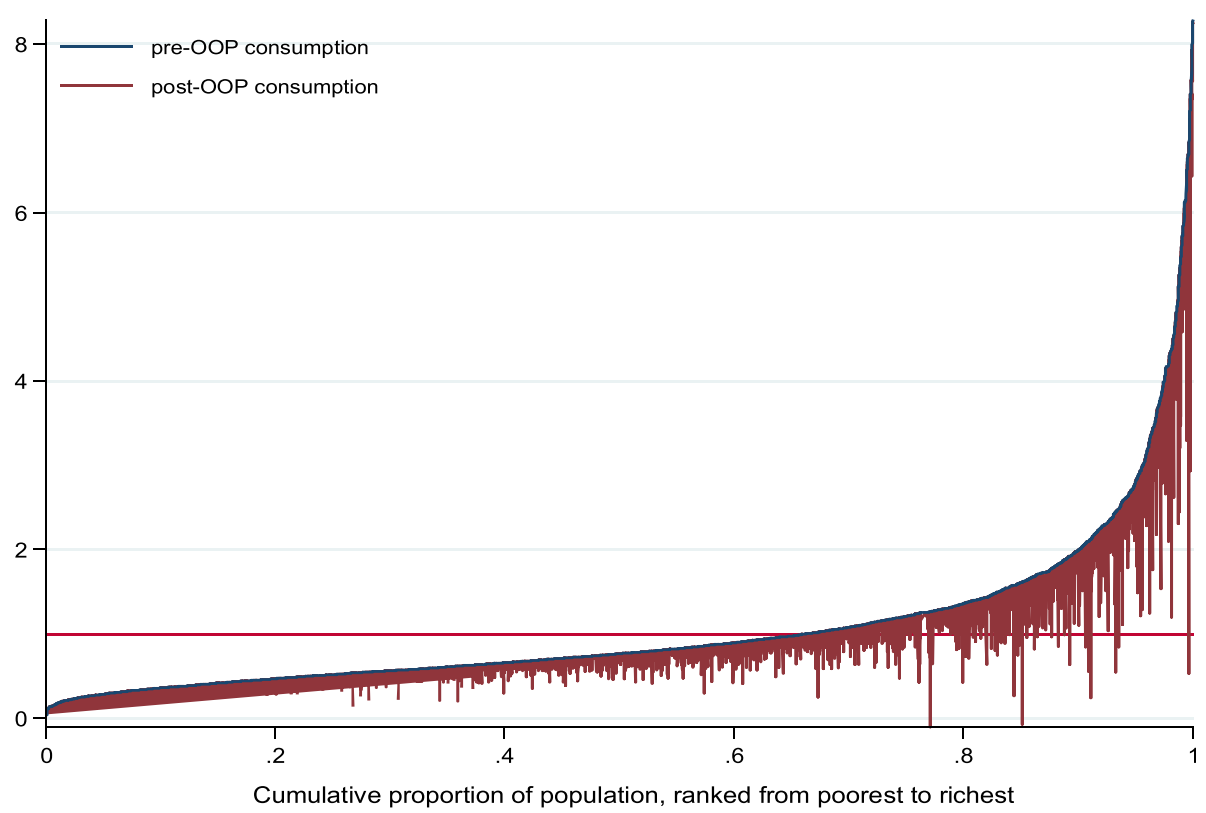

Figure 1 Pen's parade of household consumption gross and net of out-of-pocket payments. Source: Authors computations based on UNHS 2009/10. 
the knowledge of the authors, no previous studies in Uganda have analysed the impoverishment effect, the findings in this paper are similar to those reported in multi-country and other related studies [25,37-40]. Higher levels of impoverishment have been reported in other African countries especially those which, like Uganda, depend heavily on private health financing through out-ofpocket payments [41-44].

It is possible that the impact of such payments in terms of both financial catastrophe and impoverishment reported in this paper is understated. This is because the poor may be too poor to even afford falling ill and therefore modify their perception of illness so as to avoid incurring payments [22]. It may also be argued that since the poor utilise more free public facilities than the rich [12], their exposure to out-of-pocket payments is decreased. In that case, the impact is not understated. However, since the demand for public sector facilities is lower than that for private sector facilities as indicated by the preference for the latter $[13,15,16]$, it is only those who can afford to pay for the private sector services that utilise them.

The lack of financial protection as revealed in this paper has important implications for the population. There is, therefore, a need for the country to limit direct payments that impose burdens on households. Based on the international literature [1], this may take the form of moving towards prepayment (particularly mandatory) for health care as a means of attaining universal coverage. In low and middle income countries, mandatory prepayment has been shown to increase the level of financial protection [45-49]. For the private facilities where fee for service is the dominant provider payment mechanism, high out-ofpocket payments can be reduced by adopting a provider payment mechanism that does not increase household out-of-pocket expenditures.

This study has some limitations. The adjustment for vertical equity and diminishing marginal utility in the measurement of catastrophic payments as presented in this paper uses the inequality aversion parameter. The choice of the value of this parameter is still subjective [24]. Ideally, this parameter should be guided by the community's weighted preferences representing how compassionate a society is toward the poor [24]. It is still the case that the use of variable thresholds provides an indication of the manner in which societies view consideration of equity and fairness, as a small out-of-pocket payment by the very poor could be far more financially catastrophic. Furthermore, the study does not identify household characteristics that increase the likelihood of incurring both catastrophic payments and impoverishment. These are some of the areas on which, particularly in Uganda, further research on financial risk protection in a health system should focus.

\section{Conclusion}

The absence of financial protection in Uganda's health system calls for concerted action aimed at reducing the large proportion of out-of-pocket payments currently present in total health financing. The results indicate that Uganda, like many other African countries, is far from attaining the kind of universal health coverage which would emphasise protection of the poor especially. There is a need to put in place pooled prepayment systems so as to place the country on the road to achieving universal health coverage where people do not face financial difficulties in accessing the necessary health services.

\section{Competing interests}

The authors declare that they have no competing interests.

\section{Authors' contributions}

All the authors made substantial contribution to the publication of this work. $\mathrm{BK}, \mathrm{CMZ}$ and JEA were involved in the conception of the study, acquisition of the data and analysis. All the authors were involved in the drafting of the manuscript and they have all given final approval of the version to be published.

\section{Authors' information}

BK is a researcher at HealthNet Consult, Uganda. This manuscript was prepared while BK was completing his Master's degree in health economics at the University of Cape Town, South Africa. CMZ is a senior consultant at HealthNet Consult (Uganda) while JEA is a senior lecturer at the Health Economics Unit, University of Cape Town, South Africa.

\section{Acknowledgements}

The authors acknowledge funding from International Development Research Council (IDRC) for the Strategies for Health Insurance and Equity in Less Developed countries (SHIELD) project (\#106334). The Uganda Bureau of Statistics (UBOS) specifically Mr James Muwonge is also acknowledged for providing access to the Uganda National Household Survey data and Mr Paul Kizza and Ms Christabel Abewe are acknowledged for all their work on the SHIELD project in Uganda.

\section{Author details}

${ }^{1}$ HealthNet Consult, P.O. Box 35928, Kampala, Uganda. ${ }^{2}$ Health Economics Unit, School of Public Health and Family Medicine, University of Cape Town, Observatory, Cape Town 7925, South Africa.

Received: 9 August 2013 Accepted: 6 January 2015

Published online: 22 January 2015

\section{References}

1. WHO. The World Health Report 2010: Health Systems Financing: The Path to Universal Coverage. Geneva: World Health Organization; 2010.

2. Carrin G, Mathauer I, Xu K, Evans DB. Universal coverage of health services: tailoring its implementation. Bull World Health Organ. 2008;86:857-63.

3. Mclntyre D, Garshong B, Mtei G, Meheus F, Thiede M, Akazili J, et al. Beyond fragmentation and towards universal coverage: insights from Ghana, South Africa and the United Republic of Tanzania. Bull World Health Organ. 2008:86:871-6.

4. WHO. Resolution on Health Financing: A Strategy for the African Region. Geneva: World Health Organization; 2006.

5. Akin JS, Birdsall N, De Ferranti DM. Financing Health Services in Developing Countries: An Agenda for Reform. Washington D.C: The World Bank; 1987.

6. Gilson L, Mills A. Health sector reforms in sub-Saharan Africa: lessons of the last 10 years. Health Policy. 1995;32:215-43.

7. McIntyre D. Learning from Experience: Health Care Financing In Low-And Middle-Income Countries. Geneva: Global Forum for Health Research; 2007.

8. Yates R. Universal health care and the removal of user fees. Lancet. 2009;373:2078-81.

9. Burnham GM, Pariyo G, Galiwango E, Wabwire-Mangen F. Discontinuation of cost sharing in Uganda. Bull World Health Organ. 2004;82:187-95. 
10. Nabyonga J, Desmet M, Karamagi H, Kadama PY, Omaswa F, Walker O. Abolition of cost-sharing is pro-poor: evidence from Uganda. Health Policy Plan. 2005;20:100-8.

11. Tashobya CK, McPake B, Nabyonga J, Yates R. Health Sector Reforms and Increasing Access to Health Services by the Poor: What Role Has the Abolition of User Fees Played In Uganda? In: Tashobya CK, Ssengooba F, Olivera-Cruz V, editors. Health Systems Reforms in Uganda: Processes and Outputs. London: Health Systems Development Porgramme, London School of Hygiene and Tropical Medicine; 2006. p. 45.

12. Xu K, Evans DB, Kadama P, Nabyonga J, Ogwal PO, Nabukhonzo P, et al. Understanding the impact of eliminating user fees: utilization and catastrophic health expenditures in Uganda. Soc Sci Med. 2006;62:866-76.

13. Kasirye I, Ssewanyana S, Nabyonga J, Lawson D. Demand for health care services in Uganda: implications for poverty reduction. Munich: Munich University Library; 2004.

14. Orem JN, Zikusooka CM. Health financing reform in Uganda: how equitable is the proposed National Health Insurance scheme? Int J Equity Health. 2010;9:23.

15. Pariyo GW, Ekirapa-Kiracho E, Okui O, Rahman MH, Peterson S, Bishai DM, et al. Changes in utilization of health services among poor and rural residents in Uganda: are reforms benefitting the poor? Int J Equity Health. 2009;8:39.

16. Rutebemberwa E, Pariyo G, Peterson S, Tomson G, Kallander K. Utilization of public or private health care providers by febrile children after user fee removal in Uganda. Malar J. 2009:8:45.

17. Orem JN, Mugisha F, Kirunga C, Macq J, Criel B. Abolition of user fees: the Uganda paradox. Health Policy Plan. 2011;26:ii41-51.

18. WHO. National Health Accounts Database. Geneva: World Health Organization; http://apps.who.int/nha/database/Select/Indicators/en [Accessed 20 ${ }^{\text {th }}$ November 2013].

19. Ministry of Health. National Health Accounts. Tracking Resource Flows In The Health System In Uganda For The Financial Year 2008/09 And Financial Year 2009/10. 201 3. Kampala.

20. Russell S. The economic burden of illness for households in developing countries: a review of studies focusing on malaria, tuberculosis, and human immunodeficiency virus/acquired immunodeficiency syndrome. Am J Trop Med Hyg. 2004;71:147-55.

21. Whitehead M, Dahlgren G, Evans T. Equity and health sector reforms: can low-income countries escape the medical poverty trap? Lancet. 2001;358:833-6.

22. Mclntyre D, Thiede M, Dahlgren G, Whitehead M. What are the economic consequences for households of illness and of paying for health care in low-and middle-income country contexts? Soc Sci Med. 2006;62:858-65.

23. Wagstaff A, van Doorslaer E. Catastrophe and impoverishment in paying for health care: with applications to Vietnam 1993-98. Health Econ. 2003;12:921-33.

24. Ataguba JE. Reassessing catastrophic health care payments with a Nigerian case study. Health Econ Policy Law. 2012;7:309-26.

25. Niëns LM, Cameron A, Van de Poel E, Ewen M, Brouwer WB, Laing R. Quantifying the impoverishing effects of purchasing medicines: a cross-country comparison of the affordability of medicines in the developing world. PLoS Med. 2010;7:e1000333.

26. Ruhweza M, Baine S, Onama V, Basaza V, Pariyo G. Financial risks associated with healthcare consumption in Jinja, Uganda. Afr Health Sci. 2009;9:S86-9.

27. Xu K, Evans DB, Kawabata K, Zeramdini R, Klavus J, Murray CJ. Household catastrophic health expenditure: a multicountry analysis. Lancet. 2003;362:111-6.

28. World Bank. ADePT: Version 5.2. Software Platform for Automated Economic Analysis. Washington D.C: World Bank; 2012

29. StataCorp. Stata: Release 11 - Statistical Software. College Station, TX: StataCorp $L P ; 2009$.

30. Deaton A, Zaidi S. Guidelines for Constructing Consumption Aggregates for Welfare Analysis. Washington D.C: World Bank Publications; 2002.

31. Appleton S, Emwanu T, Kagugube J, Muwonge J. Changes in Poverty in Uganda, 1992-1997. Oxford: Centre for the Study of African Economies; 1999.

32. Levine S. Exploring differences in national and international poverty estimates: is Uganda on track to halve poverty by 2015 ? Soc Indicat Res. 2012:107:331-49.

33. O'Donnell O, Van Doorslaer E, Wagstaff A, Lindelow M. Analyzing Health Equity Using Household Survey Data: A Guide to Techniques And Their Implementation. Washington DC: World Bank Publications; 2008.
34. Goudge J, Russell S, Gilson L, Molyneux C, Hanson. Editorial:household experiences of ill-health and risk protection measures. J Int Dev. 2009;21 (2):159-68.

35. Van Doorslaer E, O'Donnell O, Rannan-Eliya RP, Somanathan A, Adhikari SR, Garg CC, et al. Catastrophic payments for health care in Asia. Health Econ. 2007;16:1159-84

36. Okwero P, Tandon A, Sparkes S, McLaughlin J, Hoogeveen JG. Fiscal Space for Health in Uganda: Contribution to the 2008 Uganda Public Expenditure Review. Washington D.C.: World Bank Publications; 2010.

37. Ssewanyana SN, Okidi JA. Poverty Estimates from Uganda National Household Survey III, 2005/2006. Kampala, Uganda: Economic Policy Research Centre (EPRC); 2007.

38. Knaul FM, Wong R, Arreola-Ornelas H, Méndez O. Household catastrophic health expenditures: a comparative analysis of twelve Latin American and Caribbean Countries. Salud Publica Mex. 2011;53:85-95.

39. Mills A, Ataguba JE, Akazili J, Borghi J, Garshong B, Makawia S, et al. Equity in financing and use of health care in Ghana, South Africa, and Tanzania: implications for paths to universal coverage. Lancet. 2012;380:126-33.

40. Van Doorslaer E, O'Donnell O, Rannan-Eliya RP, Somanathan A, Adhikari SR, Garg CC, et al. Effect of payments for health care on poverty estimates in 11 countries in Asia: an analysis of household survey data. Lancet. 2006;368:1357-64.

41. Ichoku HE, Fonta W, Onwujekwe O. Incidence and intensity of catastrophic healthcare financing and impoverishment due to out-of-pocket payments in southeast Nigeria. J Insur Risk Manag. 2009;4(4):47-59.

42. Chuma and Maina. Catastrophic health care spending and impoverishment in Kenya. BMC Health Serv Res. 2012;12:413. doi:10.1186/1472-6963-12-413.

43. Onwujekwe $\mathrm{O}$, Hanson $\mathrm{K}$, Uzochukwu B. Examining inequities in incidence of catastrophic health expenditures on different healthcare services and health facilities in Nigeria. PLoS ONE. 2012;7(7):e40811. doi:10.1371/journal. pone.0040811.

44. Onwujekwe O, Hanson $\mathrm{K}$, Uzochukwu B, Ichoku H, Ikeh E, et al. Are malaria treatment expenditures catastrophic to different socio-economic andgeographic groups and how do they cope with payment in southeast Nigeria? Trop Med Int Health. 2010;15(1):18-25. doi:10.1111/ j.1365-3156.2009.02418.x.

45. Knaul FM, Arreola-Ornelas H, Méndez-Carniado O, Bryson-Cahn C, Barofsky J, Maguire $\mathrm{R}$, et al. Evidence is good for your health system: policy reform to remedy catastrophic and impoverishing health spending in Mexico. Lancet. 2006;368:1828-41.

46. Limwattananon S, Tangcharoensathien V, Prakongsai P. The Impact of A Policy on Universal Coverage on Equity In Health Care Finance In Thailand. Thailand: International Health Policy Program; 2005

47. Nguyen $H$, Rajkotia $Y$, Wang $H$. The financial protection effect of Ghana National Health Insurance Scheme: evidence from a study in two rural districts. Int J Equity Health. 2011;10:4

48. Saksena P, Antunes AF, Xu K, Musango L, Carrin G. Mutual health insurance in Rwanda: evidence on access to care and financial risk protection. Health Policy. 2011;99:203-9.

49. Somkotra T, Lagrada LP. Payments for health care and its effect on catastrophe and impoverishment: experience from the transition to Universal Coverage in Thailand. Soc Sci Med. 2006;67:2027-35.

\section{Submit your next manuscript to BioMed Central and take full advantage of:}

- Convenient online submission

- Thorough peer review

- No space constraints or color figure charges

- Immediate publication on acceptance

- Inclusion in PubMed, CAS, Scopus and Google Scholar

- Research which is freely available for redistribution 